\title{
Los "ninis": jóvenes que no trabajan ni estudian en una colonia de Guadalajara Jalisco, México
}

He ido siempre con gente del barrio.

Amigos de pequeño.

Vas cambiando las amistades pero tienes cuatro o cinco amigos fijos.

Donde van ellos vas tú $y$ donde vas tú van ellos...

Carlos Feixa

Con gran sorpresa de mi parte, descubrí consultando diccionarios de afamados lexicógrafos, que habia palabras usadas por los "chavos-banda" que tenían un origen remoto en la germanía y el caló gitano del Medioevo español, lo cual me sugirió que el lenguaje marginal ha mantenido potencialmente sus características a lo largo de toda la historia del español. 
Aproximadamente la colonia se fundó en el año de 1936, con un total de 12 habitantes, encontrándose en completo abandono por parte de las autoridades de aquel tiempo. Se menciona que eran parcelas con distintos árboles frutales, había de mango, olmo, laurel, mezquite, pino, entre otros, de abi es de donde viene precisamente el nombre de Fresno, debido a la gran variedad de flora existente en la colonia...

Post anónimo de la página de Facebook del Comité Vecinal de la Colonia del Fresno, febrero de 2013

Hay, por supuesto, alguien que falta, y que deja vacíos los espacios que ocupaba, rodeado de todos los adminículos que se han quedado sin dueño, absurdos; el silencio ha crecido desde entonces. Los que se quedan presentes, habitan un ambiente que ha sido abandonado, como las ruinas, y sus comportamientos se acomodan a tal ambiente, como los fantasmas.

Pablo Fernández Christlieb

Para los que piensan que los pobres no tienen cultura, el concepto de una cultura de la pobreza puede parecer una contradicción. Ello parecería dar a la pobreza una cierta dignidad y una cierta posición.

Mi intención no es esa. En el uso antropológico el término cultura supone, esencialmente, un patrón de vida que pasa de generación en generación.

ÓSCAR LEWIS 


\section{La comida de Rancio}

La botella de salsa Valentina se vacía hasta casi la tercera parte: es la de etiqueta negra, la más picosa y temida por quienes padecen úlcera gástrica. Rancio anega con ella su paquete grande de frituras de harina de papa, disolviéndolas, volviendo el contenido de la bolsa de botanas en una mezcla acuosa color ámbar. Antes, agregó el jugo de tres limones completos, sal de grano y generosas cucharadas de una salsa mexicana, típica del barrio, la cual contiene una mezcla explosiva de jitomate, cebolla, cilantro y repollo, finamente picados, amén de sendas rebanadas de chiles habaneros frescos, casi un veneno de tan enchilosos. Rancio anuda con destreza su bolsa de churritos de medio kilo, sellándola por fuera y luego perfora con sus grandes dientes amarillentos y deteriorados su lado opuesto, realizando un pequeño orificio por donde succionará la potente mezcla para ingerirla.

“¡Es mi comida de hoy...!”, dice a la comerciante, quien también ofrece papas caseras fritas, salchichas en forma de moluscos, nieves de hielo raspado con almíbares hechos en casa, platos de fruta picada con yogurt y crema, llamados biónicos, y otras botanas. Nadie le responde, algunos clientes y curiosos se le quedan mirando, sorprendidos con la cantidad de picante que utilizó.

“¡Es mi comida...!”, insiste Rancio, tratando de llamar la atención de los niños y adultos, quienes también consumen diversas sabrosuras en el puesto de botanas. Su voz aún es de niño, con algunos gallos desafinados que anuncian su próxima entrada a la pubertad. Tiene 13 años.

Cuando dice que la bolsa de botanas es su comida, no está mintiendo. Se refiere a que realmente será el único alimento que tome en toda la tarde. Quizá en la noche consiga que alguien le regale un par de tacos de suadero o un pan con una Coca-Cola. La solidaridad con indigentes y personas de la calle por parte de los vecinos y comerciantes no es rara en la colonia. La presencia del mercado en su centro y el tianguis permanente por la Avenida Fresno son garantía para los vagabundos y teporochos, de que las sobras de la venta de alimentos nunca faltarán para el necesitado. Pero también hay probabilidades de que Rancio no coma nada hasta el otro día. 
Como no logra atraer toda la atención que quisiera, se aleja arrastrando sus pies, calzados en unos antiguos Nike de bota, desgastados y perforados de tal forma que sus dedos sin calcetines sobresalen, haciéndolos lucir más que tenis de basquetbolista como sandalias de playa.

Se tira en su esquina preferida de la calle Nogal y prosigue a succionar de la bolsa de plástico el contenido completo de su sopa de churritos con salsas y bastante limón.

A la falta de platos y cucharas, Rancio suele utilizar la misma técnica del succionado de bolsas perforadas para consumir diversos alimentos y estupefacientes. Con esta, puede comerse una torta ahogada entera, una vez que el birote salado y las carnitas y chicharrones de cerdo hayan sido suficientemente humedecidos en las salsas de jitomate y chile de árbol, como para convertirlas en un líquido tan maleable que puede atravesar sin problema el agujero de sus dientes frontales. Del mismo modo, es utilizada para inhalar el aroma mata neuronas de su "bolsazo", también conocido como "mona": algunos miligramos de solvente para muebles o resistol industrial, que son respirados con solemnidad dentro de la bolsa hasta inducir un estado de somnolencia y relajación prolongadas.

Cuando Rancio se encuentra inhalando su "mona”, parece el niño que todavía es, regresa a la época en que se chupaba el dedo o más atrás, quizá, cuando bebía leche materna del pecho de su mamá o biberón. Como si la droga fuera una forma en que el muchacho se aferrara a la ausencia de la madre, quien lo echó de su casa hace un par de años porque no le gustaba la escuela y tampoco quería trabajar.

Cerca de la noche se le ve jugando con una vieja pelota de frontón un partido contra sí mismo sobre el muro de su esquina predilecta. Aunque se junta con bastante gente y juega con variados y numerosos grupos de niños y jóvenes, no tiene muchos amigos en realidad. Sus lazos, del mismo modo que los de muchos ninis y jóvenes que abundan en esta colonia, no son en realidad demasiado profundos, sino que tienden a ser más bien superficiales. Sujetos a la conveniencia, a la oportunidad del momento, si alguien tiene algo de dinero, trae droga o algo para comer. Entonces, todos son amigos cuando hay tortillas que compartir, solvente, marihuana..., cuando no, ya no. 
Los pelotazos se escuchan hasta la una de la mañana, más o menos. Los vecinos de las calles Lima, Primavera y Nogal están acostumbrados a dormirse arrullados por el agudo golpeteo de la pelota de Rancio sobre las bardas ralladas por los grafiteros.

Pocos saben que su verdadero nombre es Ramsés, pero como los vecinos desconocen el homónimo del emperador egipcio, sobre todo los niños lo bautizaron como Rancio, al fin y al cabo suenan parecido.

La madrugada se va tranquilizando, los motores y cláxones de los autos provenientes de las grandes avenidas cercanas: Washington, Lázaro Cárdenas, Colón, Roble, etc., se acallan paulatinamente. La pelota de frontón se queda igualmente quieta.

Rancio regresa a su esquina predilecta donde come, se droga y pernocta, extrae una gruesa chamarra donada por algún piadoso de debajo de una RAM Charger 91 abandonada. Como es en extremo delgado, la prenda se convierte para él en un casi perfecto sleeping bag. Se envuelve en ella, tapando también su rostro morenísimo con su cachucha de los Bulls de Chicago, se recuesta en la banqueta, protegido a medias por la antigua RAM y es devorado por un profundo sueño hasta la mañana siguiente.

\section{El árbol de fresno de la calle Fresno y el galán don Salomé}

Don Salomé, un viudo septuagenario de oficio herrero, nativo del lugar, narró que a la Colonia del Fresno la nombraron de esa manera debido a un representativo árbol de fresno, el cual permaneció en pie hasta los años sesenta, muy cerca de lo que hoy es el mercado municipal, a partir de él se le dio ese nombre a toda la colonia. "Era un fresno casi gigante que salía de la banqueta, abarcando una parte de la calle. Cuando la ampliaron y pavimentaron, tumbaron el árbol. Ojalá lo hubieran dejado...".

Don Salomé es muy alto, viste impecable y cuida mucho su aspecto físico, es un asiduo visitante del Templo de Nuestra Señora de Lourdes, la parroquia principal. No se pierde nunca la misa de las ocho de la mañana los domingos, la que es cantada por el Coro de la Tercera Edad, medio desafinado, acompañado por dos guitarristas de más de 
setenta años, igualmente fuera de tono y desafinados. Además de su ferviente catolicismo, uno de los principales intereses de don Salomé por las liturgias del domingo, por encima de todo lo demás, son las viudas y solteronas de más de cincuenta años que no salen de la iglesia: “Tengo tres novias...”. Confiesa en una ocasión, mientras sonreía discretamente, colocando sus finos y alargados dedos medio e índice de carpintero, sobre ambos labios sensuales. En ningún momento resultó vulgar a pesar del tono de su comentario.

Cuando estuve casado era muy derecho, nunca le fui infiel a mi señora, siempre nada más del trabajo a la casa y de la casa al trabajo o a misa... No es que ahora me aproveche de que murió mi esposa, pero la verdad es que siempre me porté demasiado bien y ya estaba cansado...

Yo nací aquí en la colonia, aquí me casé y he vivido en la misma casa desde niño, donde ahora tengo mi taller... Mis hijos también nacieron aquí y dos de ellos también viven en el Fresno...

Los casos de familias dentro de la colonia que nacen, tienen hijos, nietos e incluso bisnietos, quienes permanecen o procuran quedarse en ella, son frecuentes. Hay familias cuya totalidad de sus miembros viven en la misma casa, en la cuadra o relativamente cerca, pero dentro de la colonia. Don Salomé solo llega a los nietos en su descendencia, pero está el caso de don Cacho, de casi noventa años de edad, cuyos hijos se dedican a vender tortas ahogadas, hamburguesas y burritos, y además ya tiene bisnietos de dieciséis años y no tarda en contemplar la llegada de una generación más de su simiente, pues se encuentra bastante lúcido y entero físicamente.

En el Fresno, existen tesoros insustituibles dentro de la colonia. Personajes singulares que no se verían en otro lado: gente que vive exclusivamente de sus pequeños comercios informales y a pequeña escala, talleres improvisados dentro de las viviendas que fabrican las más inesperadas cosas: artesanos, pintores, escultores, chefs, trovadores y compositores, intelectuales de izquierda que elaboran muebles de madera, tapiceros autodidactas; criadores de perros de pelea y palomas mensajeras; gente que todavía prepara pan en hornos de leña hechizos, 
en su patio, que cocina elotes, cacahuates, garbanzos y prepara tamales en tambos de hierro hervidos en hogueras y estufas improvisadas; comida de todo tipo que vuelve a la colonia una de las más ricas en variedad y diversidad culinaria, es posible encontrar casi cualquier tipo de platillo o alimento en ella, bastante bien sazonado, por cierto. Hay muchos pequeños comerciantes independientes que elaboran y venden sus productos u ofrecen sus servicios dentro de sus casas, esforzándose por dar al Gobierno lo menos o, si es posible, nada de sus ganancias a través de impuestos que cada día son más altos y difíciles de eludir.

\section{Un agujero sellado herméticamente}

La Colonia del Fresno posee particularidades que la vuelven única. Surgió en los años treinta, cuando el concepto de barrio era predominante en muchos lugares de Guadalajara y Ciudad de México. Existen algunos registros no oficiales por parte del Comité Vecinal que indican que su fundación data de 1936. Fue construida en un inicio en medio de huertas que antaño albergaron a miles de árboles: frutales y de ornamento, de donde viene su nombre "Fresno". En la memoria de los vecinos de la tercera edad, se mantiene todavía el recuerdo de cuando la colonia era muy rica en flora, con abundantes predios que contenían grandes cantidades de árboles frutales.

La colonia fue fundada cerca de las vías del tren por empleados del ferrocarril y obreros de algunas industrias construidas en la zona, quienes quisieron quedarse a vivir cerca de la estación de trenes. El Fresno es una colonia obrera y ferrocarrilera desde sus orígenes.

Los terrenos con huertas y árboles desaparecieron conforme la colonia aumentó sus calles, casas y comercios, al punto de que las áreas verdes son prácticamente inexistentes; actualmente, esto representa uno de sus mayores problemas. Del árbol del fresno y otros que algún día existieron en la colonia solo sobreviven hoy en día los nombres en sus calles: Primavera, Olmo, Nogal, Naranjo, Plátano, Pino, Roble, Mandarina, Limón, etc.

El pavimento llegó por fin en los años sesenta. La proximidad del Fresno con el ferrocarril fue al inicio una de sus cualidades e incluso ventajas, pero con el tiempo se volvió una de sus limitantes. 
Las vías de trenes fueron el principio de su aislamiento. Luego surgieron avenidas muy grandes que la fueron cercando y cerrando herméticamente: Lázaro Cárdenas, por la parte sur; Mariano Otero en el lado occidente, y, para rematar, el Tren Ligero y Avenida Colón, en el límite oriente de la colonia. Fresno quedó aislada por sus cuatro costados, por medio del ferrocarril y las grandes avenidas, encerrándola, convirtiéndola en un agujero de ratas y sabandijas, con solo dos o tres accesos limitados para entrar o salir de ella. De manera que pueden suceder muchas cosas dentro de Fresno sin que nadie que no viva dentro de ella lo sepa.

El mismo aislamiento brinda a sus habitantes una mentalidad muy particular; a pesar de sus problemas, la mayoría de ellos no quieren irse de la colonia. Hay familias que permanecen por generaciones y que siguen queriendo vivir en ella. Mucha gente nace en la colonia, trabaja dentro de ella, se casa con personas de aquí mismo, elabora y vende sus cosas en el mismo lugar. Dado que es posible encontrar todos los servicios y productos dentro, si alguien se lo propone, no necesitaría salir prácticamente del Fresno jamás.

La sensación de un espacio cerrado, casi hermético, cuyos patrones culturales siguen repitiéndose a lo largo de décadas, vuelve al Fresno un campo de estudio rico y fascinante para cualquier estudioso. Personajes como Rancio, don Salomé y don Cacho, entre muchos otros, son sujetos interesantísimos a los cuales seguir la pista.

También, lo son la cantidad de jóvenes, ligados y prisioneros de estos patrones, que abandonaron la escuela; incluso algunos de ellos como Rancio no saben leer ni escribir. Tampoco trabajan y no hacen otra cosa más que pasar las tardes inhalando sustancias, fumando hierba, navegando en sus teléfonos celulares y mirando pasar la vida sin ninguna prisa.

\section{Vías de acceso a la Colonia del Fresno}

La Colonia del Fresno se encuentra en el municipio de Guadalajara, uno de los principales puntos urbanos de la ciudad cerca del centro histórico. Aunque son pocos los accesos para entrar y salir de ella - principalmente las avenidas Roble y Fresno, que desembocan, a 
su vez, en la avenida Washington, en Lázaro Cárdenas y en Colón, por donde circula el tren ligero- desde el Fresno se tienen vías que conectan a casi cualquier parte de la ciudad: hacia Chapultepec, cruzando Washington, y puede accederse hasta el centro de Zapopan por las avenidas México y Américas; hacia el centro de Guadalajara, se puede circular a través de Washington y Enrique Díaz de León; hacia el sur de la ciudad, por Cruz del Sur y Mariano Otero. A esta última puede accederse siguiendo directamente la calle Primavera, cuyo nombre hace honor al florido árbol de primaveras y es una de las calles más bonitas del Fresno, con sus fachadas antiguas, pero bien cuidadas, atraviesa la colonia entera desde Colón y desemboca en la planta de la Cervecería Corona, en Lázaro Cárdenas y M. Otero. Rumbo a las salidas hacia el Estado de Colima y la Ciudad de Morelia a través de la clásica Plaza del Sol, conectando con López Mateos. También hacia la Central Camionera Nueva y el aeropuerto, si se quisiera, siguiéndose la amplia, de cuatro carriles y de dos niveles, Lázaro Cárdenas.

El tren ligero y la avenida Colón, donde se encuentra el primero, constituyen una vía fundamental de acceso hacia el Fresno. La estación del tren que se detiene en la colonia es Santa Filomena. Los obreros, los estudiantes, los empleados y las personas que no poseen automóvil pueden transportarse a cualquier lugar de la ciudad a través del tren. La avenida Colón, al cruzar Washington e ingresar en el paso a desnivel, se convierte en Federalismo, atravesando toda la ciudad de Guadalajara de sur a norte, culminando en el periférico con sus salidas hacia Tlajomulco y Tlaquepaque, o hacia el norte, prácticamente en la carretera a Saltillo y Zacatecas; y desde allí, si se deseara, hasta la frontera norte de México con los Estados Unidos.

\section{Comercio y contradicciones insalvables}

La Colonia del Fresno posee una paradoja insalvable, inherente a su ubicación y construcción histórica. Aunque las grandes avenidas, industrias ubicadas en sus fronteras y el ferrocarril la han aislado geográficamente por sus cuatro costados, también se encuentra bastante bien conectada casi hacia cualquier parte de la ciudad. Pese a 
su hermetismo geográfico, en el Fresno existe un inmenso comercio: formal, informal y subterráneo, facilitado por su proximidad con el mercado de abastos, el centro de la ciudad y las salidas hacia otros Estados. Su comercio es tan vasto que no se limita solo al mercado municipal ni a sus alrededores, sino que se extiende a cada rincón, a casi cada casa.

Dentro de la colonia, puede encontrarse prácticamente cualquier tipo de negocio, producto y servicio, sea público o privado. Hacia ella recurren personas provenientes no solo de colonias vecinas, sino incluso de lugares bastante lejanos del sur de la ciudad tan solo para adquirir las cosas que se venden en ella, consumir en sus cenadurías, restaurantes y puestos ambulantes de tacos, lonches, crepas, nieves, molletes, hot cakes, etc., por las noches. Las grandes papelerías que existen no se dan abasto en surtir los útiles escolares de los habitantes del Fresno, sino que mucha gente de otros lugares llega a ellas por su accesibilidad y para no tener que ir hasta el centro de Guadalajara en épocas de inicio de clases en las escuelas. Las tiendas de regalos y perfumerías y el tianguis navideño por la calle Fresno tampoco cesan de tener movimiento, sobre todo hacia el mes de diciembre, época en que la colonia ve saturados sus espacios hasta su máxima capacidad.

La mentalidad de una gran cantidad de habitantes de la colonia es la del típico comerciante, que busca adquirir productos y servicios a bajo costo para venderlos un poco más caros con la esperanza de obtener alguna ganancia. Por ende, la escolaridad tiende a ser baja, aunque existen profesionales: médicos, profesores, contadores públicos, homeópatas, podólogos, odontólogos y psicólogos, que habitan y ofrecen sus servicios dentro de ella. No son raros los casos de niños y jóvenes como Rancio que abandonaron la escuela primaria en los primeros años o que incluso jamás han pisado un aula escolar. Rancio, de hecho, no sabe leer ni escribir.

La estructura de agujero hermético, aislada en sus fronteras de la colonia, facilita del mismo modo el comercio ilegal de estupefacientes y drogas. El Fresno también es conocido por el tráfico de drogas y el narcomenudeo, hacia la colonia van también a adquirir los productos de su mercado negro, sobre todo en horas cercanas a la madrugada. 


\section{Rockeros, hip-hoperos, norteños-banda y trovadores}

Aunque el comercio y los comerciantes sean los que predominen y posean el control casi absoluto de la colonia, los músicos y artistas son bien vistos y respetados. En el Fresno, hay orquestas, bandas, mariacheros, tríos, norteños, raperos y los infaltables clanes de rockers que se unifican en diversos momentos y puntos de encuentro, aunque no dejan de subdividirse y marcar sus categorías propias, como los que se identifican con el punk hardcore, el reggae y el ska; están también los que escuchan e interpretan covers del heavy metal clásico, con sus agrupaciones emblemáticas que en los barrios jamás se olvidan a pesar del paso de los años: Led Zeppelin, Guns and Roses, Motley Crue, Iron Maiden, Black Sabath, Kiss, Bon Jovi, etc. El sincretismo musical sorprende, por las diferencias de edad entre las personas que pueden escuchar la misma música: niños, púberes, adultos e incluso gente de la tercera edad, que corean como pueden las canciones en inglés y español; así como por la mezcla indistinta de géneros musicales, épocas y estilos, donde importa solo el sentimiento y el estado de ánimo.

Del mismo reproductor de discos compactos o de la desgatada bocina para tocar Mp3 importada de China, puede emerger con igual probabilidad Paranoid de Black Sabath, que Terrenal de Julión Álvarez, la inolvidable Stairway to Heaven de Led Zeppelin, la melancólica Desvelado de Boby Pulido, Nowhere Man de los Beatles, Vía Láctea del grupo mexicano Zoe, o algo pegador y nada desdeñable, interpretado por los Invasores de Nuevo León.

Está el caso de don Luis, un cantante autodidacta de más de sesenta años, quien padece temblores seniles; desconfiado, arisco y discreto habitante del Fresno, quien jura haber ayudado a Álvaro Carrillo a componer algunos de sus boleros más memorables. Igualmente, señala haber sido aguador del luchador Blue Demon en los años sesenta y más tarde también luchador, aunque nunca ha querido revelar qué personalidad de la lucha libre encarnó. Con sus manos temblorosas, debido a la senectud, cuida a sus niños por la mañana, prepara la comida y hace sus mandados; mientras su mujer, la China, veinte años más joven que él, trabaja como administrativa en una aseguradora durante todo 
el día. Don Luis todavía escucha viejos casetes en una antigua grabadora marca Zonda y cuando sus hijos se van a la secundaria a la una de la tarde, se pone a entonar con su reproductor de cintas olvidadas canciones de los Tecolines, los Panchos y Javier Solís.

También está don Memo, obrero calificado de la planta Flextronic del Periférico Sur. Tiene 44 años y aborda todos los días el transporte de personal de su empresa a las seis de la mañana por la calle Roble. Cuando regresa por la tarde, lo esperan sus tres niñas, su mujer y su perro Shrek: una cruza de Pit Bull y American Stanford, enorme, nobilísimo y amable con los niños. Entonces, extrae de su estuche su guitarra de Paracho Michoacán para rascarle los mejores boleros y baladas, en inglés y español. Don Memo es una encarnación del sincretismo cultural y musical más entremezclado que puede producirse en el Fresno; canta muy bien en español e inglés: rolas de The Beatles, Bee Gees, Carol King y The Carpenters de los años sesenta y setenta; de igual modo que viejas baladas de Los Terrícolas, La Revolución de Emiliano Zapata, Los Ángeles Negros y Los Pasteles Verdes: antiguas agrupaciones románticas provenientes de la década de los setenta y ochenta. Aprendió inglés cuando cruzó de mojado la frontera con Estados Unidos para trabajar como jardinero. Don Memo se pasa luego a los boleros, los cuales toca en un estilo muy personal, casi cercano a la balada rítmica con voz suave, discreta, de tenor. Tiene una colección de más de mil discos compactos de todo tipo de música y también le gusta criar perros Pit Bulls, aunque jamás los usa para pelea. El viejo Shrek es su semental más apreciado. Tras una tarde de sesión musical en su casa, no es raro verlo caminando hasta la avenida Washington en compañía del imponente Shrek, con su bolsita de plástico para recoger las heces fecales del fornido animal.

En géneros musicales, también están los “perreros”, subiendo hacia un tono de mayor violencia verbal y sexual, son los que escuchan y bailan reguetón, aunque dentro del sincretismo cultural de la colonia, estos mismos también pueden pasarse fácilmente a otros géneros y escuchar o identificarse con los que aprecian el reggae, rock, hip-hop, norteño-banda y balada pop, sin que a nadie le preocupe u ofenda.

Si el tono se sube aún más hacia una escalada mayor de la violencia auditiva, entonces llegan los asiduos a los narcocorridos, que cada 
día ganan mayores adeptos entre niños y adultos. No se sabe si estos realmente pertenezcan a grupos del crimen organizado y si debido a ello gusten de este tipo de música, o simplemente intenten imitar a los narcos en su forma de hablar, conducirse y en la música que presuntamente les gusta.

\section{Los mercados de pulgas $\mathrm{y}$ el tianguis de las vías}

La estructura geográfica de agujero hermético del Fresno no solamente influye en la repetición de patrones culturales de sus habitantes, en la música que los vecinos y comerciantes ponen de moda al escucharla incesantemente unos y otros a todo volumen, o en su mentalidad particular; los objetos también permanecen encerrados dentro de la colonia, se reciclan y circulan en su interior pasando de las manos de un habitante a otro y recorriendo sus calles y casas: la ropa usada que ha cambiado de dueño más de dos o tres veces; los muebles viejos que se revenden e intercambian no solo en una ocasión, mudados de una casa o una vecindad a otra; los relojes y libros antiguos, que quizá le fueron arrebatados a alguien en cuestionables circunstancias, o se recogieron furtivamente en algún desalojo de las casas abandonadas e incluso de la basura; los zapatos reparados, parchados, zurcidos, pintados y vueltos a comerciar; los juguetes que transmigran de generación en generación de niños del Fresno.

Los objetos tienden a vivir una vida larga dentro de la colonia, varios dueños y un camino prolongado de diversos hogares donde son adoptados, reconstruidos y a veces reconstituidos desde sus fundamentos.

En la colonia, hay varios puntos clave en donde se pueden encontrar todo tipo de objetos usados, reparados y reciclados a la venta. Está el espacio asignado los jueves para la ropa usada en la calle Limón, conocido como Lemonpool, tanto por los comerciantes como por su fiel clientela, no sin cierto sarcasmo, haciendo referencia a la lujosa tienda departamental Liverpool, a la cual la mayoría de ellos no tienen acceso. Grandes cantidades de prendas de segunda mano para todas las edades y tallas, en ocasiones casi nuevas, se pueden encontrar 
en todo el corredor formado por esta calle, a un costado del mercado municipal, donde se instalan decenas de comerciantes. La mercancía es procedente de Estados Unidos y al parecer, no siempre es legal, pues en más de una ocasión se han presentado decomisos por parte de las autoridades. Cientos de personas tanto del Fresno como de colonias aledañas e incluso distantes se congregan los jueves por la mañana para surtir sus guardarropas.

El tianguis de las vías, ubicado en las calles Fresno y Olmo, que aunque se lleva a cabo principalmente los jueves y domingos, resulta permanente durante toda la semana, pues buena parte de sus comerciantes se instalan el resto de los días, aunque no sea tianguis, para proseguir sus ventas y obtener nuevos productos. En las vías puede encontrarse de todo: ropa, zapatos usados, jaulas para pájaros, relojes, muebles, animales o electrodomésticos. Todo viejo, muy viejo y de segunda y hasta tercera mano. Es posible, con suerte, descubrir invaluables tesoros: arte, antigüedades, pinturas, libros viejos o muebles de buena calidad. Esto comprueba cómo los objetos dentro de la colonia son "viajeros": poseen una larga vida y pasan de persona en persona. Circulan, se les recicla, se reparan y transforman al interior del hoyo negro sin fondo que es el Fresno. Los llamados “coyotes" asisten a las vías todos los jueves y domingos en busca de valiosísimas reliquias de las que se sabe luego revenden en bazares y galerías de otras colonias más lujosas.

Aunque pueden identificarse tanto la calle Limón como el tianguis de las vías como puntos emblemáticos de la venta de cosas usadas, prácticamente en todo el Fresno pueden hallarse pequeños bazares, tenderetes en las aceras, entradas de las casas y cocheras donde es factible que la gente venda la ropa y objetos viejos, ya sea recogidos en la calle, que alguien se los pasó para sacar un poco de dinero o fueron parte de sus mismas pertenencias y objetos personales con los que ahora desean obtener algo de ganancia.

\section{Estudiar a los “ninis” en su entorno}

El término "nini” fue acuñado, por una parte, por diversos medios periodísticos y de prensa en México, y por otra, al mismo tiempo, fue 
popularizado por la misma población de las clases y colonias populares de todo el país, como el Fresno, con la cual trabajamos, para referirse a la creciente población de jóvenes, desde la pubertad hasta muy entrada la etapa adulta, que abandonaron la escuela, interrumpieron sus estudios o los finalizaron, pero no prosiguieron a la etapa siguiente o jamás entraron a la escuela, como Rancio.

Otra de las características indiscutibles del "nini” es que además de no estudiar, tampoco se ha integrado al campo laboral. No trabaja por ningún motivo ni se dedica a ninguna actividad que resulte productiva en la apariencia. En ese sentido, "nini” es un término peyorativo e incluso despectivo, burlesco y despreciativo. Empero, como se verá enseguida, los mismos "ninis" reconocen pertenecer a este grupo, a veces con cierta vergüenza, con resignación, pero también con comodidad.

El "nini” vive en una especie de limbo social, construido sobre la base de juegos de video, tecnologías de comunicación diversas: internet, teléfonos móviles (a veces de última generación), drogas y estupefacientes, comida chatarra, bandas y pandillas no muy formales que se aglutinan en colonias como el Fresno, desde las once de la mañana (pues desde luego no se levantan temprano, ya que no tienen obligaciones), y que permanecen en las esquinas de los barrios y espacios públicos como parques de colonias de interés social e, incluso, en sectores sociales pudientes hasta muy entrada la noche. Beben, se drogan, navegan en internet, hablan con otros "ninis" en condiciones similares, etc.

Casi siempre, como se verá también, tienen a la figura de una madre, soltera, sola, divorciada, separada del padre o aislada de él, la cual sustenta de un modo directo o indirecto, desde el punto de vista financiero, su vida límbica, socialmente letárgica y comodina.

Los “ninis”, a su vez, no son fáciles sujetos de estudio. Esquivos, tímidos, deprimidos, tienden a ocultarse, por pena y vergüenza. Como se encontró, la mayoría de ellos son muy conscientes de su condición. Algunos se levantan o despiertan hasta después del medio día. Es posible localizar a otros solo hasta altas horas de la noche, cuando se reúnen con sus coetáneos en las esquinas y las banquetas.

Se trató de observar la vida cotidiana de algunos "ninis" en la Colonia del Fresno, como observadores participantes y, en menos ocasiones, como entrevistadores cualitativos, cuando se podía, dependiendo 
del momento de la investigación. Retomando por una parte la fenomenología y la sociología cualitativas como método epistemológico y de trabajo:

Since our purpose in this treatise is a sociological analysis of the reality of everyday life, more precisely of knowledge that guides conduct in everyday life... We must begin by a clarification of that reality as it is available to the common sense of the ordinary members of society. (Berger y Luckman, 1999, p. 31)

Desde la perspectiva de este trabajo, coincidiendo con la sociología del conocimiento, el sentido común de los habitantes del Fresno, particularmente de los “ninis", será el objeto de estudio. Por otra parte, buscamos inscribirnos, también, en la relativamente novedosa corriente que busca retratar la vida cotidiana de las culturas urbanas, tribus de jóvenes y no tan jóvenes que viven en las ciudades, elaboran sus propios códigos de pensamiento y comunicación y sobreviven como pueden, adaptándose a las problemáticas de la vida en las urbes (Feixa, 1998; Marcial, 2006).

\section{El hijo de la directora}

Ramón fue dejado a los diez días de nacido por su mamá en casa de sus abuelitos, en Ciudad Guzmán. Ahí vivió con ellos hasta que tenía doce años e iba a ingresar a la secundaria. Ella se regresó a la ciudad porque le acababan de asignar su plaza como profesora de educación primaria en Guadalajara. Su mamá actualmente es directora de una escuela primaria que se encuentra en la misma Colonia del Fresno, aquí viven tanto Ramón como su mamá, quien también trabaja dentro de la misma zona.

La madre de Ramón reconoce que la parte más importante de la infancia de su hijo transcurrió lejos de ella, con sus abuelitos, quienes lo maleducaron sobremanera, le compraban todo lo que él quería y les pedía, lo que, en la actualidad, es uno de los principales problemas que presenta Ramón en su vida como "nini”: es un comprador insaciable de objetos de tecnología de última generación (teléfonos móviles, reproductores de DVD, videojuegos, etc.). Ahora Ramón no solo 
pide cosas a su mamá, sino que le exige que se las compre a toda costa, con amenazas de agredirla si no se le complace en sus demandas.

Ramón también consume sin parar comida chatarra: pollo Kentucky Fried Chicken, pastelillos, papitas, frituras con chile y nieves. Él come todo el día, tanto lo que su mamá le prepara a sus horas de alimentos como diferentes tipos de golosinas, botanas y panes. Para ello, dispone de todo el dinero que desea, pues su madre se lo proporciona sin freno ni restricción alguna.

Ramón tiene actualmente dieciséis años, hasta los doce vivió en Ciudad Guzmán y, posteriormente, antes de ingresar a la secundaria, comenzó a vivir con su mamá en Guadalajara.

La madre de Ramón le facilita todos los recursos económicos posibles para poder sustentar su vida como "nini”, sin ningún límite. Cuando cuestionamos al respecto a la profesora, su mamá, ella nos indicó que apenas lo está conociendo, que tiene pocos años viviendo con él, pero le parece que es un muchacho que puede llegar a ser muy violento y posee bastante fuerza. En más de una ocasión la ha agredido físicamente cuando ella se niega a facilitarle dinero para comprar lo que desea.

Al respecto del término "nini”, es el propio Ramón quien se expresa, esclareciéndonos otros conceptos propios de los jóvenes de su actualidad, su vida apegada a las redes sociales y las consecuencias que tiene no ir a la escuela:

¿Que a qué me dedico...? A “Nini”... Soy “Nini”... Terminé la secundaria nada más, inicié unos semestres de la prepa, pero no me gustaba. Me echaban mucha carrilla porque yo venía de un pueblo y aquí en la ciudad la gente es bien maliciosa.

Bueno, a veces veo a otras personas que van a la secundaria, a la prepa y a la universidad y me da nostalgia. Sí se me antoja. A lo mejor en una de esas me ven volviendo a la escuela. Un "nini” no va a la escuela pero tampoco hace otra cosa, no va a trabajar ni quiere hacerlo. Ni tiene prisa por hacer nada. Estoy muy a gusto como estoy. A veces le ayudo a mi mamá a preparar la comida y pienso: sería buen chef, podría estudiar gastronomía. Pero no 
terminé la prepa, perdí mi lugar en la $U$ de $G$ porque no iba a clases y ahora tendría qué acabarla en una privada. Empezar desde el principio o una semiescolarizada. Y no más de pensarlo me da mucha flojera. La verdad es que estoy bien como estoy, a lo mejor algún día sí estudio para chef o pongo un puesto de comida, de tacos o algo así, porque la verdad me queda muy bueno todo lo que preparo.

La mayoría del tiempo me la paso chequeando el Facebook estalkeando las cuentas de muchachas bonitas.

¿Qué qué es estalkear...? Principalmente, es espiar los muros y las cuentas de personas que te llaman la atención, pero que no te agregaron a sus redes sociales o no son tus amigos ni nunca lo serán...

Ramón posee un teléfono móvil de última generación, bastante grande y con mucha capacidad. Como él mismo dice, su teléfono es su pequeña computadora. En él consulta Wikipedia (porque, a pesar de todo, es un muchacho que lee bastante en internet, investiga muchas cosas y tiene una amplia cultura cibernética), descarga juegos y pasa todo el día entretenido; también, revisa sus redes sociales, particularmente Facebook, busca chistes, bromas y noticias cómicas, encuentra pornografía, mira películas en su teléfono, principalmente de manga y animé japonés. Escucha música y la descarga. Bastante de su tiempo en el teléfono lo dedica a revisar la cuenta de muchachas que no pertenecen a su red, las localiza por sus rostros agradables; Ramón señala que le gustan las chicas del tipo oriental: con los ojos rasgados y los rasgos faciales muy finos. Si puede y si no lo tienen bloqueado, ingresa en sus muros y se la pasa admirando sus fotografías durante horas, aunque ellas no se den cuenta, no sepan jamás quién es él ni tampoco Ramón se atreva de ningún modo a contactarlas, enviarles solicitud de amistad ni mucho menos a hablar con ellas.

En un arranque de sinceridad, con lágrimas en los ojos, Ramón confesó que es demasiado tímido con las mujeres, aunque le agradan muchísimo y quisiera tener una novia. Sin embargo, considera que no es agradable a la vista de las muchachas: tiene sobrepeso, es bastante 
alto (mide poco más de $1,90 \mathrm{~m}$ de estatura) y su rostro se encuentra cubierto de espinillas y granos blanquecinos, típicos de la pubertad.

A escondidas, fuera de la vista de su madre, luego de mirar largo rato las fotografías de mujeres en redes sociales o en alguna página de chicas desnudas, Ramón acude a encerrarse en el baño de su recámara para masturbarse y descargar todo el cúmulo de sus deseos sexuales adolescentes, frustraciones por no encajar en los estereotipos sociales ni haber continuado con sus estudios.

Para el año 2011, aproximadamente un total de 7,5 millones de jóvenes pertenecían, igual que Ramón, a la categoría de "ninis"; es decir, jóvenes menores de edad que no iban a la escuela, no trabajaban ni realizaban ninguna labor productiva (Negrete Prieto y Leiva, 2013).

Según los cálculos estadísticos reportados por Negrete en el Inegi, en México la cifra tiende a crecer alarmantemente, abarcando porcentajes de hasta el 20 y el $25 \%$ de aumento de jóvenes por año que no trabajan y han abandonado la escuela, o no salen en listas de las preparatorias y universidades; mucho menos trabajaban. Para el 2015, apenas cuatro años después, el periódico La Jornada publicó la arriesgada cifra de 39 millones de jóvenes como pertenecientes a dicha categoría poblacional, en los 34 países que integran la Organización para la Cooperación y el Desarrollo Económicos (OCDE). Señaló que el rango de edad de esta población oscila entre los 16 y los 29 años de edad (Poy Solano, 2015), y crece alarmantemente en cantidades que aumentan a 5000 por año.

Los autores de este libro consideran que puede ser que el rango de edad sea más grande, es decir, que quizá comiencen a ser "ninis" desde los 13 o 14 años, como hemos observado en la Colonia del Fresno.

Los "ninis", según los reportes de la OCDE, deberían constituirse en sus sociedades, como activos económicos, dado que se encuentran en la plenitud de sus vidas. Es decir, contribuir a la economía, iniciar negocios, pagar impuestos, emprender proyectos e iniciativas. Empero, la realidad es otra, grandes cantidades de jóvenes que no son admitidos en la preparatoria o la universidad, pero que sí terminan alguna de estas etapas escolares, aunque ya no siguen estudiando ni trabajando, se vuelven más bien pasivos económicos, es decir, representan cargas 
sociales económicas para sus familias, quienes tienen que continuar manteniéndolos aunque ellos se encuentren en edades productivas.

Ser "nini” es una enfermedad crónica. En la Colonia del Fresno es un padecimiento que no se cura con ninguna cosa, y que tiende a empeorar con los años. Los jóvenes "ninis" se pasean por las calles de la colonia hasta altas horas de la noche, se pelean entre ellos, consumen estupefacientes, molestan a los niños, a otros jóvenes de su edad que sí realizan alguna actividad o a los vecinos. Se hacen más grandes y mayormente improductivos con el paso del tiempo y no parecen tener ninguna prisa por volverse activos laboral o académicamente.

Ramón nos cuenta que hace unos meses, junto con un grupo de "ninis", apedrearon a una ancianita. Su madre, la maestra, salió no a proteger a la anciana ni a frenar a los agresivos muchachos, sino a defender a Ramón porque la señora ya había tenido problemas con su hijo y siempre lo regañaba y lo culpaba de todo. Se alcanza a elucidar que pareciera que tal cantidad de jóvenes desocupados, sin ningún oficio, beneficiaran indirectamente el sistema social mexicano tal como se encuentra.

¿Qué sucedería si todos esos jóvenes que no estudian ni trabajan se pusieran a leer, fueran conscientes de sus derechos y exigieran a sus gobernantes las múltiples omisiones de las que son víctimas?

Pareciera que los “ninis", aunque cada día son más y también constituyen un problema, convienen para sostener el estatus del sistema tal como se encuentra. Casos como el de Rancio, huérfano y completamente analfabeto y vulnerable, y Ramón, con el apoyo y la complicidad plena de su mamá, son dos tipos de "ninis" que encontramos al interior de la Colonia del Fresno. 


\section{Bibliografía}

Berger, P. y Luckman, T. (1999). The social construction of reality: A treatise in the sociology of knowledge. USA: Penguin Books.

Feixa, C. (1998). De jóvenes, bandas y tribus. Barcelona: Ariel.

Fernández Christlieb, P. (1994). Teorías de las emociones y teoría de la afectividad colectiva. Extraordinario de 1994. Ixtapalapa: UAM.

Fernández Christieb, P. (2001). La psicología colectiva un fin de siglo más tarde. Barcelona: Anthropos.

Garfinkel, H. (2006). Estudios en etnometodología. Barcelona: Anthropos.

Lewis, O. (1961). Los hijos de Sánchez. México D. F.: Joaquín Mortíz.

Marcial, R. (2006). Andamos como andamos porque somos como somos. Culturas juveniles en Guadalajara. México D. F.: El Colegio de Jalisco.

Negrete Prieto, R. y Leiva, G. (2013). Los ninis en México, una aproximación crítica a su medición. Realidad, datos y espacio. Revista Internacional de Estadística y Geografía.

Poy Solano, L. (2015). En México, 7 millones de los 39 millones de ninis que hay en naciones de la OCDE. La Jornada. Recuperado de http:/www. jornada.unam.mx/2015/05/28/sociedad/038n1soc

Taylor, C. y Bogdan, S. (2001). Introducción a los métodos cualitativos de investigación. Barcelona: Paidós. 
